\title{
TOWARDS AUTOMATED ROAD INFORMATION FRAMEWORK A CASE STUDY OF TANZANIA
}

\author{
Angela-Aida K. Runyoro ${ }^{1 *}$, Irina Zlotnikova ${ }^{1}$ and Jesuk Ko ${ }^{2}$ \\ ${ }^{1}$ School of Computational and Communications Science and Engineering, Nelson Mandela \\ African Institute of Science and Technology, P.O. Box 447, Arusha, Tanzania \\ (Ph.: +255-754-985-989. E-mail: runyoroa@nm-aist.ac.tz) * Corresponding author \\ ${ }^{2}$ Department of Healthcare Management, Gwangju University, Gwangju 503-703, Korea
}

Traffic congestion problem has been noticed to have a serious impact on the economy of the country in terms of time wastage, energy consumption costs, human loss and environmental effects. Different strategies have been used so far all over the world as shown in the literature review. Intelligent Transportation System (ITS) is a multi-technology approach that can help to handle the issues and create a complete congestion reduction framework. This paper presents a case study for implementing automated road management system using networks in Tanzania, where three cities highly affected by traffic congestion have been studied. Study results show that these cities have not yet implemented new technologies in road traffic management; instead the traffic is controlled using traffic police officers and traffic lights only. The traffic lights use an old technology that cannot manage traffic in relation to the real-time situations. This study proposes components for a framework, which will assist automation in road traffic management. From the review of various existing ITS of which Advanced Traffic Management System (ATMS) and Advanced Travel Information System (ATIS) are subsystems, we have identified the possibility to integrate the two sub-systems within the framework. Three-phase traffic theory has been referred, FOTO and ASDA models are applied to the automatic recognition and tracking of congested spatiotemporal traffic patterns on roads.

Keywords: Traffic Congestion, Urban Transportation, Intelligent Transportation Systems (ITS)

\section{Introduction}

Traffic congestion is a growing problem in most urban areas all over the world. Tanzanian urban areas are among the most affected. Intelligent Transportation Systems (ITS) apply Information and Communications Technologies (ICT) to the real-time management of vehicles and transportation system as a whole involving the movement of people, goods and services. When integrated into the transportation system's infrastructure, and into vehicles, these technologies relieve congestion, improve safety and enhance productivity [1]. Despite of the benefits and opportunities brought by ITS, the major problem is how to introduce them in developing countries with many challenges in network infrastructure and economic problems.

Therefore, Tanzania as one of the developing countries can embark technology, which is suitable in relation to the country set-up and culture, in order to solve the traffic congestion problem. Development of a framework to be adopted is important so as not to cause failure in solving the problem. This paper attempts to explicitly investigate, evaluate, analyse and present the state of traffic congestion control together with issues and challenges as results of current ongoing research conducted in three urban networks located in three cities of Tanzania, namely (1) Arusha, (2) Mwanza and (3) Dar es Salaam. Tanzania has been chosen as a case study for two reasons. First, two of the authors live and work in this country and know its problems best of all. Second, Tanzania is a typical country of sub-Saharan Africa with the GDP per capita of $\$ 1,700$, and it is in early stages of applying technology in traffic management.

Hassan [2] stated that reasons such as inadequate transport infrastructure, rapid increase in urban population, income and automobile ownership etc., had been noted to contribute to traffic congestion in many of the urban areas. However, expanding the transportation systems is not always fruitful, if the demand is not satisfactorily met by the existing capacity. As such it is necessary to optimise the use of existing transportation system by using certain management techniques [3]. There exist a number of traffic control mechanisms, which either controls supply side of the traffic only or demand side of the traffic information only. The demand reflects both origin destination patterns and the combination of all individual decisions of travellers. ATIS, by influencing drivers' travel decisions, are therefore designed to influence transportation demand side. The supply reflects the state of transportation network in terms of infrastructure, traffic flow and traffic control. ATMS impose certain restrictions and constraints on traffic flows, which result in modification of the capacity of networks. Therefore they affect transportation supply side [4]. 
This paper proposes an automated road information framework, which will enable the implementation of better traffic control networked systems in Tanzania. The framework considers issues and challenges in managing the traffic flow faced by the country. These include (1) poor infrastructure, (2) limited budget and (3) lack of expertise in technology advancements. The review of available ITS, in relation to the challenges faced by the country, has revealed that the automation in three studied cities should also involve integration of supply and demand sides of the transportation systems.

The general objective of the study is to develop an automated road information framework this will enable better traffic flow management in Tanzanian cities, through the use of networked systems. The specific objectives are as follows:

(1) To identify issues and challenges of using networked systems in urban traffic flow management

(2) To identify strengths and weaknesses of existing ITS

(3) To identify components of the automated road information framework and links between them.

The paper structure is as follows: introduction; overview and state of traffic congestion control; research methodology; results; discussion, conclusion and further work.

\section{Overview of Road Traffic Management}

\subsection{Technologies available}

The overview of currently available within Tanzania road traffic management systems such as traffic lights has shown that these systems have no ability to adjust to the recurring or non-recurring situations [8]. Instead they continue to function like in a normal situation. Traffic lights behave in the same way during the peak and normal hours and even during special situations such as parade, accident, floods and etc.

As explained in [9], the traffic lights were implemented in the period where there was no technology advancement. Tanzania like other developing countries still relies on traffic lights. Whenever the traffic lights fail to perform their work of controlling traffic flow at the road junctions, they are substituted by traffic police officers who manually manage the traffic flow. This arrangement has not been helpful in solving the traffic congestion problem the country is currently facing. Tanzania could integrate the currently used mechanism of controlling the traffic with advanced systems to mitigate the traffic congestion problem. There are several systems, which have been implemented in various countries with the purpose of managing the traffic flow. Table 1 gives a list of some countries, which have implemented ITS. It also indicates strengths and weaknesses of the systems. While developing the automated road information framework, the authors tried to incorporate strengths and avoid weaknesses of the existing systems.

Table 1. Some examples of the existing ITS

\begin{tabular}{|l|l|l|l|}
\hline \multicolumn{1}{|c|}{ Country } & \multicolumn{1}{|c|}{ Implemented ITS } & \multicolumn{1}{c|}{ Strengths } \\
\hline $\begin{array}{l}\text { South } \\
\text { Korea [5] }\end{array}$ & $\begin{array}{l}\text { Real-time traffic information provision; } \\
\text { Advanced public transportation } \\
\text { Information systems; Electronic fare } \\
\text { payment and electronic toll collection }\end{array}$ & $\begin{array}{l}\text { Built on city by city } \\
\text { basis, formed ITS Model } \\
\text { cities }\end{array}$ & High implementation cost \\
\hline Japan [6] & $\begin{array}{l}\text { VICS (Vehicle Information and } \\
\text { Communication } \\
\text { System), ETC (Electronic Toll Collection) } \\
\text { AHS (Advanced Highway System), UTMS } \\
\text { (Universal Transportation Management } \\
\text { System) }\end{array}$ & $\begin{array}{l}\text { Satellite based, guide } \\
\text { users everywhere } \\
\text { including minor roads }\end{array}$ & High implementation cost \\
\hline $\begin{array}{l}\text { The Unites } \\
\text { States of } \\
\text { America [5] }\end{array}$ & $\begin{array}{l}\text { Variable rate high way tolling; Electronic } \\
\text { toll collection; Advanced traffic } \\
\text { management systems such as ramp } \\
\text { metering, and travel information provision }\end{array}$ & $\begin{array}{l}\text { ITS effort focuses on } \\
\text { research }\end{array}$ & $\begin{array}{l}\text { ITS vary significantly by } \\
\text { state and region and are not } \\
\text { integrated into a national }\end{array}$ \\
\hline $\begin{array}{l}\text { South } \\
\text { Africa [7] }\end{array}$ & $\begin{array}{l}\text { An automated system, including incident } \\
\text { management for providing incident } \\
\text { information, ramp metering, toll collection } \\
\text { and public transport priority system }\end{array}$ & $\begin{array}{l}\text { Implementation in } \\
\text { stages }\end{array}$ & Non digitised road networks \\
\hline
\end{tabular}




\subsection{Implementing ITS}

It has been reported in [10] that ITS as a whole is too large and complex to install all at once even in the wealthiest and most technically advanced countries. In most countries, including both developed and developing countries, the right approach is to introduce ITS gradually and in stages, focusing first on the parts of ITS that provide the greatest value in proportion to cost. Therefore, the successful introduction of ITS must include staging, and planning for change, growth, and ongoing integration as new functions are introduced and existing.

An ITS architecture is a valuable tool for describing how ITS will work and for defining its major building blocks. There already exist many good ITS architectures like these presented in Table 1.Therefore, it is not necessary for a country with limited resources like Tanzania to develop its own ITS architecture from scratch. It is generally faster and less expensive to start from an existing architecture and adjust it step-by-step to the country's requirements [10].

\subsection{ITS subsystems}

The Intelligent Transportation System (ITS) uses sensing, processing and communication technologies. As reported in [11], ITS comprises four main subsystems presented on Figure 1, these are Advanced Traffic Management System (ATMS), Advanced Travel Information System (ATIS), Advanced Public Transport System (APTS) and Emergency Management System (EMS).

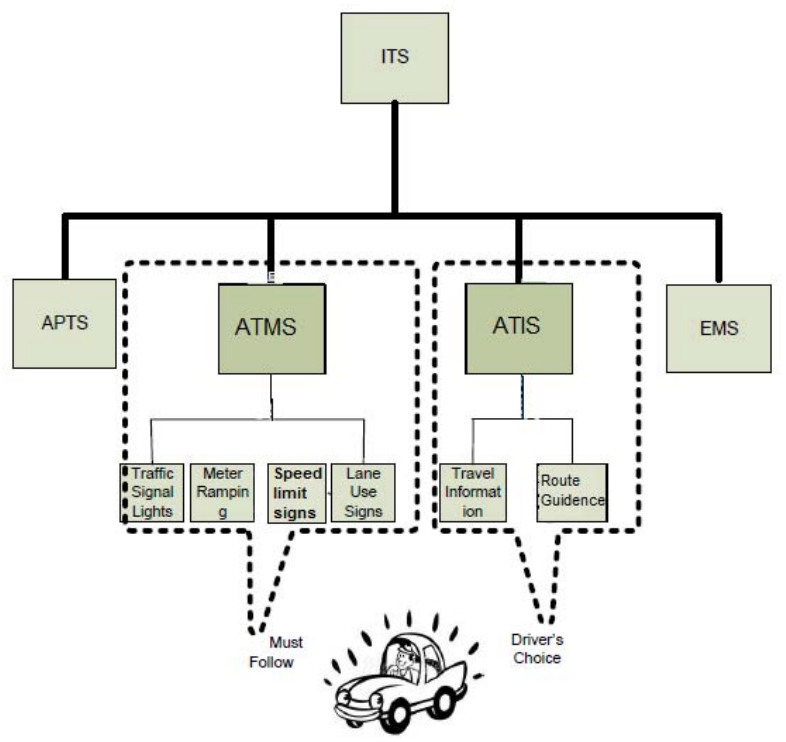

Figure 1. ITS and subsystems of ITS (Source: [11])

Of those subsystems ATMS and ATIS are most important to the proposed automated road information framework. Their functions listed in Table 2 can easily complement the functions of the existing road management system (namely traffic lights), which currently operates in Tanzania.

Table 2. Functions of ITS subsystems

\begin{tabular}{|l|l|l|}
\hline ITS Subsystem & Functions & Cited in \\
\hline Advanced Public Transport System (APTS) & Public Transport Management & {$[10]$} \\
\hline $\begin{array}{l}\text { Advanced Traffic Management System } \\
\text { ATMS) }\end{array}$ & Sets constraints and limits on the traffic flows & {$[11]$} \\
\hline $\begin{array}{l}\text { Advanced Travel Information System } \\
\text { ATIS) }\end{array}$ & Provide travellers with the travelling information & {$[11]$} \\
\hline Emergency Management System (EMS) & $\begin{array}{l}\text {-Emergency notification and personal security } \\
\text {-Emergency vehicle management }\end{array}$ & {$[12]$} \\
\hline
\end{tabular}


ATMS integrates the management of various roadway functions. It predicts traffic congestion and provides alternative routing instructions to vehicles. ATMS collects, utilizes and disseminate real-time data to road users and further alerts for alternative routes to improve transit operations. Devices used to form the ATMS include(1) traffic signal lights, (2) meter ramping, (3) speed limit signs and(4) lane use signs.

The ATIS combines travel information and route guidance systems. Drivers can access the information while they are in their vehicles, in their homes or at their places of work. Information provided includes: (1) location of incidents, (2) weather problems, (3) road conditions, (4) optimal routings, (5) lane restrictions, and (6) in-vehicle signing. Information can help drivers, passengers and even pedestrians to decide what transport mode and route they should opt for.

Incident detection is of high importance for ATMS and ATIS to function well, as they respond in relation to what has been detected. In relation to the research findings, Tanzania is in good position to start with the implementation of ATMS and ATIS subsystems, since the two systems can easily integrate with the existing traffic control systems such as traffic lights.

\section{Methodology}

Research methodology is based on qualitative and quantitative research methods. Research process is divided into two stages. The first stage included literature review in the area of road traffic management and automation. The second stage employed a research survey, whereby questionnaires and in-depth interviews were conducted in order to collect the relevant data.

Three Tanzanian cities (Dar es Salaam, Mwanza and Arusha) have been identified as most affected by road traffic congestion problem [13]. Three government organizations responsible for roads management in each city have been approached, namely: (1) Traffic Police;(2) Municipal Councils and (3) Tanzania National Roads Agency (TANROADS). Road users - drivers and non-drivers (passengers) have been also included into survey.

Different types of questionnaires were delivered to the targeted interviewees based on their levels within the organization. These levels included: (1) strategic level (directors and decision makers), (2) technical level (senior technical staff) and (3) operational level (technical staff). 10 questionnaires were distributed in each organization, in all the three cities. A total of 90 respondents were contacted during the interview; of those 86 responded. For the road users, the sample size was calculated based on Eq. (1) [14]:

$$
s=\frac{X^{2} N P(1-P)}{d^{2}(N-1)+X^{2} P(1-P)},
$$

where

$s$ is the required sample size;

$X^{2}$ is the table value of chi-square for the first degree of freedom at the desired confidence level (3.841);

$N$ is the population size;

$P$ is the population proportion (assumed to be 0.50 since this would provide the maximum sample size);

$d$ is the degree of accuracy expressed as a proportion (0.05).

For the three cities, a total of 1,200 road users were contacted, but only 1,100 of those responded to the questionnaires.

\subsection{Traffic Flow Theory}

In this paper, three-phase traffic theory by Kerner is referred. In this theory, the phases in traffic are consisting of free flow and two congestion phases: synchronized flow and wide moving jam. Forecasting of Traffic Objects (FOTO) model, which identifies traffic phases and tracks synchronized flow, together with Automatische Staudynamik analyse: Automatic Tracking of Moving Jams (ASDA) model are applied to the automatic recognition and tracking of congested spatiotemporal traffic patterns on roads [15].

As inputs, ASDA/FOTO model needs traffic volumes and speeds; the output is the current situation of traffic objects over the detected section. In this paper we are focusing on ATMS and ATIS 
as main components of the proposed framework. The main requirement of these two components is the real time traffic information. This information is derived from ASDA/FOTO model and then applied to the components. Road users' decision to travel depends on the information disseminated to them using ATIS.

In three phase theory, velocity $v$, density $\rho$ and flow rate $q$ of vehicles are related by the expression

$q=\rho v$

FOTO/ASDA analyses average speeds and flow rates. Traffic phases are identified based on the following rules:

(i) FOTO/ASDA detects synchronized flow, when

$v \leq v_{s y n}$

(ii) FOTO/ASDA detects a wide moving jam, when

$v<v_{j a m}$ and $q<q_{j a m}$

(iii) FOTO/ASDA detects free flow, when

$v>v_{s y n}$,

where by $v$ and $q$ are average speed and flow rate measured at each time step. The speeds $v_{s y n}, v_{j a m}$ and the flow rate $q_{j a m}$ are model parameters.

\section{Results and Discussion}

\subsection{Field Survey Data Analysis}

\subsubsection{Roads Management}

It has been found in the field survey that traffic flow management is mainly controlled by traffic police officers $(42.0 \%)$ and traffic lights $(36.3 \%)$. These responses, as summarized in Table 3 , indicate higher percentage compared to other means of traffic management.

Table 3. Responses to applied traffic management procedures

\begin{tabular}{|l|c|c|}
\hline \multicolumn{1}{|c|}{ Implemented Procedure } & Frequency & Percent \\
\hline Use of traffic lights & 729 & $36.3 \%$ \\
\hline Use of traffic police officers & 844 & $42.0 \%$ \\
\hline Speed limit signs & 168 & $8.4 \%$ \\
\hline Real-time electronic sign boards & 26 & $1.3 \%$ \\
\hline Radio announcements & 100 & $5.0 \%$ \\
\hline Use of road bumps & 143 & $7.0 \%$ \\
\hline
\end{tabular}

The results also show that there is no automated traffic flow management system currently implemented in Tanzania. However, there is high utilization of electronic devices such as mobile phones, computers, radio and television. These devices can be easily integrated into the transportation systems allowing users' access to the information.

Dissemination of the road status information to the road users is very important because the users would like to have a pre-informed travel. The study found that $82.6 \%$ of the respondents from the responsible organizations, agreed to disseminate road information to road users, while only $17.4 \%$ of the respondents disagreed. 
Different kinds of information disseminated by the road management organizations are presented on Figure 2. Mainly the disseminated information concerns road construction work in progress $(39.2 \%)$ and closed/fault roads (22.5\%). Information concerning traffic congestion and road accidents is provided in less than $20 \%$ of cases.

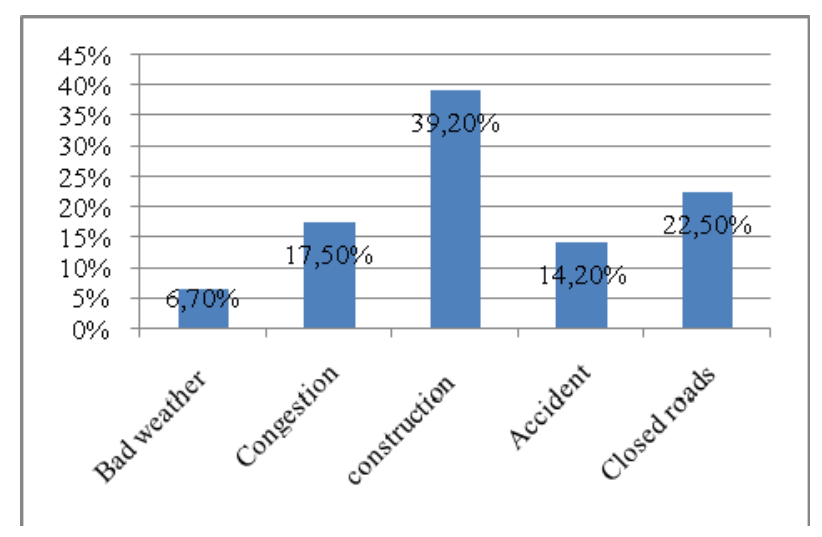

Figure 2. Distribution of different kinds of road information disseminated by road management organizations

As explained in Section 2.1, it is important to consider both recurring and non-recurring situations when disseminating road information to the road users. The study has shown that the disseminated information in the three cities is only concentrating on recurring situations. It is not automated, and the dissemination is done using the wooden signboards. This does not allow the road users to be able to plan for their travel. Therefore a system that can consider both recurring and non-recurring situations in road traffic management is needed.

\subsubsection{Road users}

It has been noted that road users are experiencing traffic congestion problems during the peak hours when most of them use the roads for either going to the workplace in the morning or going back home in the evening. This statement is supported by the results from three surveyed areas as presented in Table 4. These results show that congestion happens mostly in the morning and evening as per evidenced percentages of $49.3 \%$ and $47.2 \%$ respectively. This was measured based on the time road users spent to reach a specific destination from a pre-set origin.

Table 4. Distribution of congested periods during the day

\begin{tabular}{|l|c|c|}
\hline Time of the Day & frequency & Percentage \\
\hline Morning (06:00am $-11: 59 \mathrm{am})$ & 943 & $49.3 \%$ \\
\hline Afternoon $(12: 00 \mathrm{pm}-04: 59 \mathrm{pm})$ & 66 & $3.5 \%$ \\
\hline Evening $(05: 00 \mathrm{pm}-08: 00 \mathrm{pm})$ & 903 & $47.2 \%$ \\
\hline
\end{tabular}

Regarding possible means by which the road users could access the road information, the respondents indicated that majority of them would be able to receive the information through radio and mobile phones; this is evidenced by $31.4 \%$ and $30.9 \%$ respectively as indicated in Table 5 .

Table 5. Possible means of receiving road information for the road users.

\begin{tabular}{|c|c|c|}
\hline Means & Frequency & Percent \\
\hline Internet / Website & 301 & $14.7 \%$ \\
\hline Mobile phone & 631 & $30.9 \%$ \\
\hline Radio & 641 & $31.4 \%$ \\
\hline Television & 385 & $18.8 \%$ \\
\hline Visiting information source & 85 & $4.2 \%$ \\
\hline
\end{tabular}




\subsection{Components of the Proposed Framework}

Figure 3 indicates how components are networked in the proposed automated road information framework for managing Tanzania roads' traffic flow. The framework considers integration of systems, which controls both the traffic demand and supply sides. The road users require both sides information for enabling smooth traffic flow. The central control connects road users to the supply and demand services of the transportation system.

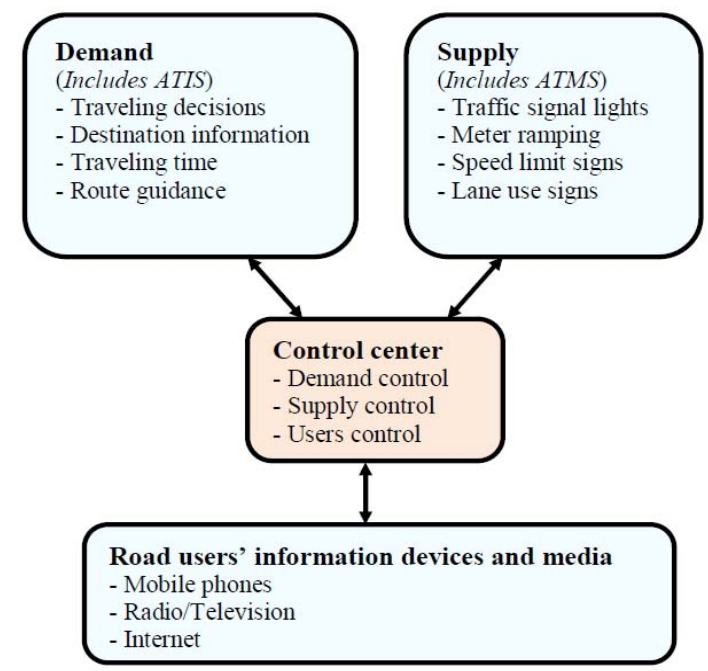

Figure 3. Networked components of the proposed automated road information framework

\subsubsection{Demand side systems}

The demand side of the proposed automated road information framework is considered in this study as an integration of all systems and services, which deals with road information distribution and management. Pre-trip information helps the road users to plan and travel while knowing the current situation on the road. This helps the users not to waste their time in traffic jams, but instead make an informed decision of using alternative roads with lower or no congestion.

The demand side includes ATIS. Its components provide the following functionality:

(1) Travelling decisions systems help travellers decide what roads to choose to avoid congestion

(2) Destination information systems give an alert concerning situations occurring on specific destinations

(3) Travelling time systems estimate the time needed to travel from a specific origin to destination

(4) Route guidance systems decide on the routes to be followed in order to reach a particular destination.

\subsubsection{Supply side systems}

The supply side includes ATMS. It mainly concentrates on the management of the traffic flow on the roads network. ATMS components provide the following functionality:

(1) Traffic signal lights, which control the traffic flow at road junctions using the timed signals for allowing or stopping the traffic flow

(2) Meter ramping controls the number of vehicles allowed to enter a highway

(3) Speed limit signs assist drivers in keeping within the given speed limit

(4) Lane use signs alert drivers on the main lanes the presence of merging vehicles and send appropriate warnings.

\subsubsection{Control Centre}

This is a central merging unit, where all ITS sub-systems are controlled. Road users are connected to the demand and supply services through the control centre. 


\subsubsection{Road Users' Information Devices and Media}

Road users' information retrieves or requests to the central control are done through communication devices and media such as mobile phones, radio/ television and Internet.

\section{Conclusion and Further Work}

The study has shown that currently in Tanzania the traffic flow is managed manually while the only implemented road management systems are traffic lights. ITS existing in developed countries cannot be adopted as-is due to their high cost, size and complexity, so the best way is to introduce them gradually, step-by-step. In this paper we have indicated procedure for Tanzania to introduce ITS by effective utilization of available technologies, such as mobile phones and Internet. This study has identified the components that can be integrated into ITS. These include (1) demand side systems such as ATIS; (2) supply side systems such as ATMS; (3) control centre; (4) road users' information devices and media. Future work will involve integrating more services into the supply and demand side, as well as implementation and testing of the prototype of the automated road information system.

\section{References}

1. Samadi, S., et al. (2012). Performance Evaluation of Intelligent Adaptive Traffic Control Systems: A Case Study, Journal of Transportation Technologies, 2, 248-259. Doi:10.4236/jtts.2012.23027. Published Online July 2012 (http://www.SciRP.org/journal/jtts).

2. Hasan, M. K. (2010). A Framework for Intelligent Decision Support System for Traffic Congestion Management System. Engineering, 2, 270-289. Doi:10.4236/eng.2010.24037. Published Online April 2010 (http://www. SciRP.org/journal/eng).

3. Caldow, J. (2008). Feeling the Pain: The Impact of Traffic Congestion on Commuters. Institute for Electronic Government, IBM Corporation.

4. Ben-Akiva, M., et al. (2002). Real time simulation of traffic demand-supply interactions within DynaMIT. Applied Optimization, 63, 19-34.

5. Ezell, S. (2010). Explaining international IT application leadership: Intelligent transportation systems (p. 2). The Information Technology \& Innovation Foundation.

6. Hollborn, S. (2002). Intelligent Transport Systems (ITS) in Japan. Tokyo: Institute of Industrial Science, University of Tokyo.

7. Vanderschuren, M. (2006). Intelligent Transport Systems for South Africa, Impact Assessment through Microscopic Simulation in the South African Context. Cape Town - the Netherlands: University of Cape Town and University of Twente.

8. Hallenbeck, M. E., J. Ishimaru \& J. Nee. (2003). Measurement of recurring versus non-recurring congestion. Washington State Transportation Commission, Department of Transportation in cooperation with, U.S. Department of Transportation, Federal Highway Administration.

9. Figueiredo, L., et al. (2001). Towards the development of intelligent transportation systems. In Proceedings of the IEEE Conference 'Intelligent Transportation Systems', 2001. IEEE.

10. Yokota, T. \& R.J. Weiland. (2004). ITS system architecture for developing countries. Transport and Urban Development Department, World Bank.

11. Rahman, M., S. Rehmat \& G. Khattak. (2012). A Secure and Intelligent Transportation System Using Wireless Sensors for Congestion Control. Applicable operational methods to alleviate traffic congestion in Pakistan.

12. Smadi, A. \& K. Miner. (2005). Intelligent Transportation Systems (ITS), State wide Plan. North Dakota: North Dakota State University.

13. Mrema, G. D. (2011). Traffic Congestion in Tanzanian Major Cities: Causes, Impact and Suggested Mitigations to the problem. In Proceedings of the $26^{\text {th }}$ National Conference (p. 01). Institution of Engineers Tanzania (IET).

14. Krejcie, R. V. \& D. W. Morgan. (1970). Determining Sample Size For Research Activities. Educational and Psychological Measurement, 30, 607-610. Morgan Texas A. \& M. University.

15. Kerner, S. B. (2009). Introduction to Modern Traffic Flow Theory and Control. The Long Road to Three-Phase Traffic Theory. Berlin Heidelberg: Springer-Verlag. ISBN 978-3-642-02604-1. 